\title{
Risk Analysis of Flare Flame-out Condition in a Gas Process Facility
}

\author{
O. Zadakbar ${ }^{*}$, R. Abbassi ${ }^{1}$, F. Khan ${ }^{1}$, K. Karimpour ${ }^{2}$, M. Golshani ${ }^{2}$ and A. Vatani ${ }^{3}$ \\ 1 Faculty of Engineering \& Applied Science, Memorial University of Newfoundland, St. John's, NL, A1B 3X5 - Canada \\ 2 Nargan Consulting Engineers, Tehran - Iran \\ 3 Institute of Petroleum Engineering, Faculty of Engineering, University of Tehran, Tehran - Iran \\ e-mail: o.zadakbar@mun.ca - rabbassi@mun.ca - fikhan@mun.ca-k.karimpour@nargan.com-m.golshani@nargan.com - avatani@ut.ac.ir \\ * Corresponding author
}

Résumé - Analyse des risques des conditions d'extinction de torche au sein d'une installation de traitement de gaz - Le torchage est un procédé courant d'élimination des gaz résiduaires inflammables dans les industries de traitement. L'extinction de la torche (par décollage ou soufflage de flamme) provoque souvent une émission de vapeurs toxiques. Ces gaz toxiques libérés peuvent présenter des effets dangereux sur le milieu environnant. Pour étudier l'effet d'une exposition par inhalation de ces gaz toxiques sur la santé, cet article croise les quatre étapes de la démarche de l'EPA (Environmental Protection Agency, Agence de protection de l'environnement) avec les données d'exploitation afin de quantifier le risque sanitaire cancérologique et non cancérologique. Dans le cadre de l'estimation d'exposition, une modélisation de dispersion des gaz utilisant AERMOD et UDM-PHAST est évaluée dans deux configurations différentes de torchage normal et d'extinction de torche à l'occasion de conditions climatiques particulières dans la région du Khangiran. L'article propose également des recommandations destinées à éviter les conditions d'une extinction de flamme de torche.

Abstract - Risk Analysis of Flare Flame-out Condition in a Gas Process Facility - Flaring is a common method of disposal of flammable waste gases in the downstream industries. Flare flame out (flame lift-off or blow-outs) often occurs causing toxic vapors to discharge. The toxic gases released may have hazardous effects on the surrounding environment. To study the effect of inhalation exposure of these toxic gases on human health, the four steps of the EPA (Environmental Protection Agency) framework with the field data to quantify the cancer and non-cancer health risks are integrated in this paper. As a part of exposure assessment, gas dispersion modeling using AERMOD and UDM-PHAST is applied in two different conditions of normal flaring and flare flame out during a particular climate condition in Khangiran region. Recommendations to avoid flare flame out conditions are also presented here. 


\section{INTRODUCTION}

Refinery flares are used for the safe disposal of flammable waste gases from emergency process upsets as well as for start-up, shut-down and turnaround operations. Flaring could release large quantities of $\mathrm{SO}_{2}$ and $\mathrm{CO}$ into the atmosphere. The magnitude of emissions resulted from flaring process in Iran is not clear, as many refineries do not have flare monitoring and emissions recording procedures in place. Thus, there is a concern about the potential underestimation of reported emissions released during flaring processes [1].

In the downwind plume of sour gas flares, $\mathrm{SO}_{2}$ and $\mathrm{H}_{2} \mathrm{~S}$ exist, in addition to a wide spectrum of sulfur-containing chemicals and the range of unburned hydrocarbons. An annual exposure greater than $4 \mu \mathrm{g} / \mathrm{m}^{3} \mathrm{H}_{2} \mathrm{~S}$ is associated with spontaneous abortion in humans and animals [2]. The odor threshold of $\mathrm{H}_{2} \mathrm{~S}$ is approximately $7 \mu \mathrm{g} / \mathrm{m}^{3}$, which is less than the critical concentration. An acceptable daily intake of $1.8 \mu \mathrm{g} / \mathrm{m}^{3} \mathrm{H}_{2} \mathrm{~S}$ has been presented [3].

Combustion efficiency of a flare is severely affected by wind. Regardless of the regulatory stricture imposed, a conventional flare will never operate above $95 \%$ of efficiency except in wind speed of about less than $2 \mathrm{kmph}$ [4]. Reduced combustion efficiency must be regarded possible in any operation with flaring. Simultaneous low combustion efficiency causes release of unburned gas. That includes hydrogen sulfide with sour gas flares.

Public health concerns about gas flaring have existed for many years in different regions near natural gas facilities. Some of these concerns are related to potential long term cumulative health effects on humans from exposure to hazardous chemical concentrations released during incomplete combustion of flare gases [5]. Environmental Risk Assessment (ERA) evaluates the nature and likelihood of the adverse effects on human health and ecosystems due to the environmental changes [6]. Implementing the four steps of EPA (Environmental Protection Agency) framework of risk assessment process with chemical concentrations during flare flame out and normal flaring demonstrated in Figure 1, lead to evaluate the effects of these concentrations emitted due to the flare gases on the human health [7].

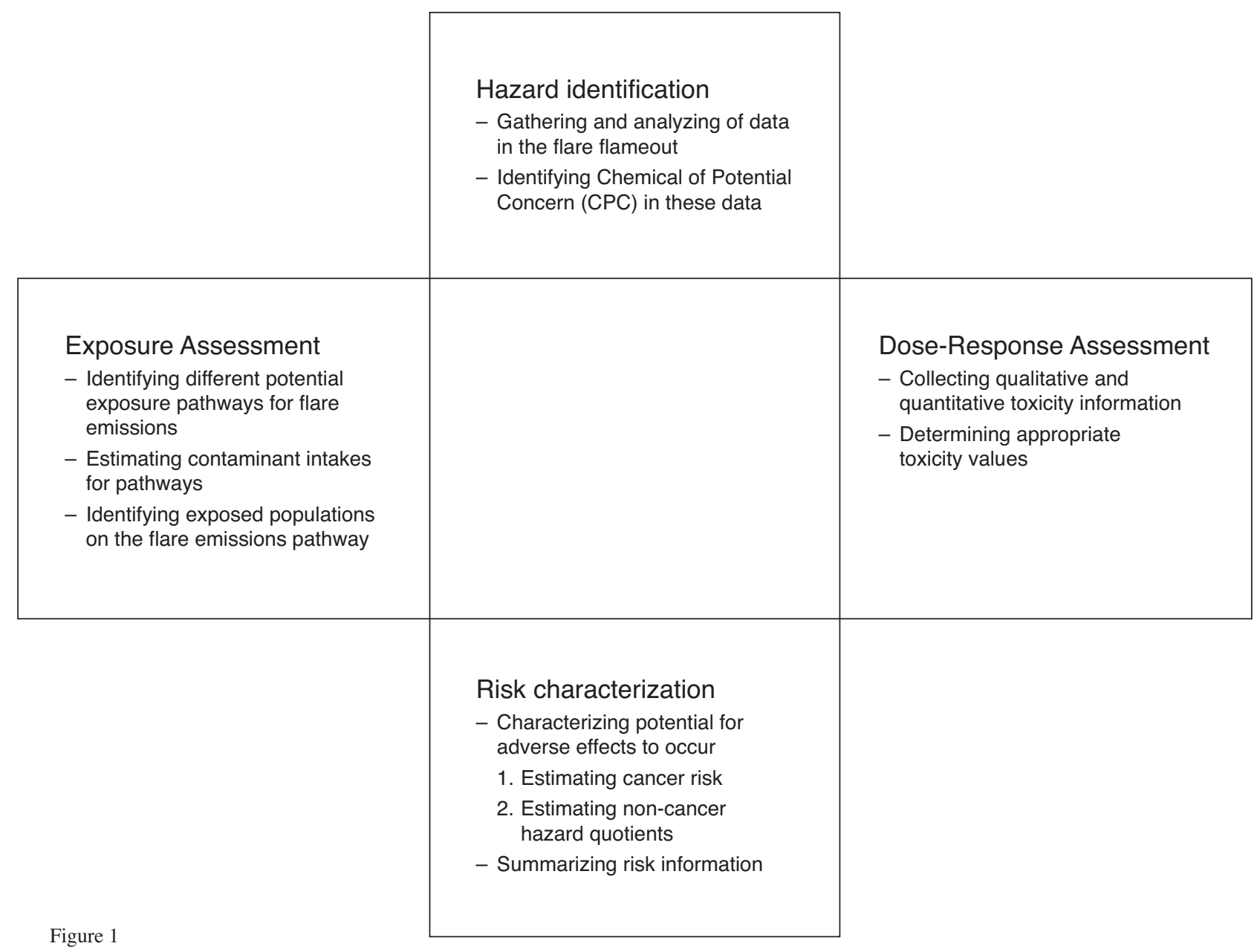

ERA methodology for evaluating the human health risk of the flare emissions. 
Risk-based evaluation of chemical concentrations during normal flaring as well as flare flame out via a case study in the Khangiran gas process facility (Sarakhs-Iran) is considered in this paper. Recommendations for precluding the flame out conditions are also presented.

\section{ENVIRONMENTAL RISK ASSESSMENT}

\subsection{Site Specification}

The Shahid Hashemi-Nejad (Khangiran) natural gas process facility is one of the most important gas process facilities, located in northeastern Iran in an open inhabitable range land, semi arid and dusty with windblown sand (Fig. 2). The feed gas is supplied from the Mozdouran gas fields. This gas process facility consists of 5 sour gas treating unit, 3 dehydration units, 3 sulfur recovery units, 2 distillation units, 2 stabilizer units and 14 additional units related to other services [8].

The wind direction in the Khangiran vicinity is from northwest to southeast. This condition occurs in the Khangiran gas process facility for $90 \%$ of a year. For the remainder of the year, the wind direction changes, and the wind blows from southeast to northwest [10]. This means that for about $10 \%$ of the year, personnel are in danger of inhaling more toxic gases. During this period, the personnel are exposed to an unacceptable amount of toxic gases which could affect their health. Wind roses were used to give a succinct view of how wind speed and direction are typically distributed and to determine the direction of the prevailing wind in the vicinity of Khangiran. During 10\% of the year, the wind direction is 160 degrees [10], which causes the wind to carry toxic gases to the personnel dormitory. This dormitory is located 1050 meters away from the flare stack and it is 200 meters in length. The release time was considered to be $1 \mathrm{~h}$.

\subsection{Hazard Identification}

The toxic gases considered during the release time $(1 \mathrm{~h})$ has been studied and calculated for two flaring conditions:

- Flare flame out, in which the concern gas is $\mathrm{H}_{2} \mathrm{~S}$;

- Normal flaring, in which the concern gas is $\mathrm{SO}_{2}$.

$\mathrm{H}_{2} \mathrm{~S}$ (Hydrogen Sulfide) is an extremely hazardous and toxic compound. $\mathrm{H}_{2} \mathrm{~S}$ is colorless and flammable which can be identified by its characteristic rotten egg odor. Low concentrations of 20-150 ppm $\mathrm{H}_{2} \mathrm{~S}$ cause irritation of the eyes, slightly higher concentrations may cause irritation of the upper respiratory tract, and if exposure is prolonged, pulmonary edema may result. The irritant action has been explained on the basis that $\mathrm{H}_{2} \mathrm{~S}$ combines with the alkali present in moist surface tissues to form sodium sulfide, a caustic [11]. As the concentration approaches $100 \mathrm{ppm}$, odor becomes impressible due to olfactory fatigue. At these levels, the gas disrupts cellular respiration and may cause profound respiratory depression as well as cardiac dysrhythmias [12]. A high concentration of $200 \mathrm{ppm}$ is extremely hazardous and can immediately be life threatening [13]. Inhalation of

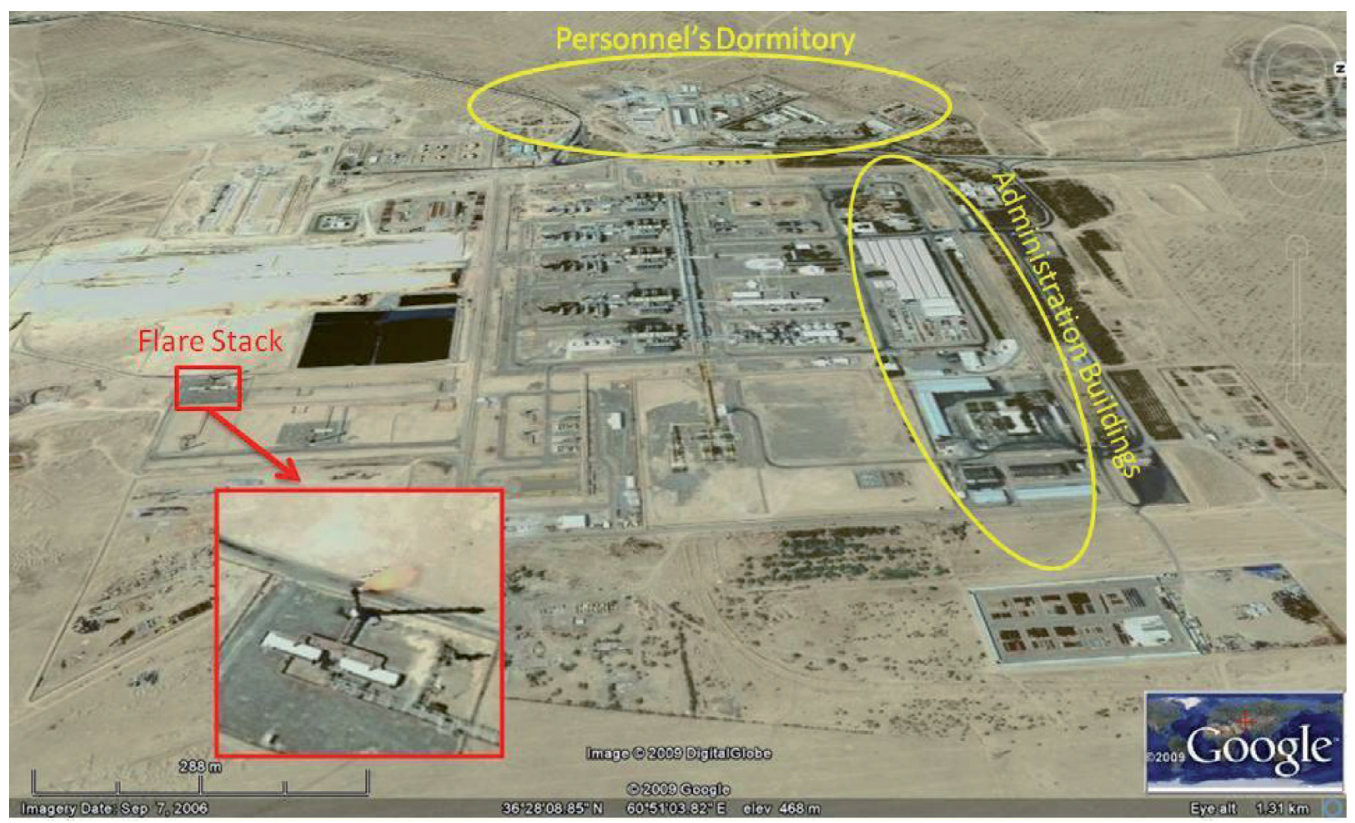

Figure 2

Khangiran gas process facility and surrounding areas [9]. 
$500 \mathrm{ppm}$ for 30 minutes produces headache, dizziness, excitement, staggering, and gastroenteric disorders, followed in some cases by bronchitis or bronchial pneumonia. Concentrations above $600 \mathrm{ppm}$ can be fatal within $30 \mathrm{~min}$ utes through respiratory paralyses [14].

Furthermore, $\mathrm{SO}_{2}$ is a colorless gas which smells like burnt matches. It can be oxidized to sulphur trioxide, which in the presence of water vapor is readily transformed to sulphuric acid mist. $\mathrm{SO}_{2}$ with acute exposure of 5 ppm may cause dryness of nose and throat and a miserable increase in resistance to bronchial air flow. $\mathrm{SO}_{2}$ increasing up to 6 to $8 \mathrm{ppm}$ causes a decrease in tidal respiration volume. Sneezing, cough \& eye irritation occur at $10 \mathrm{ppm} . \mathrm{SO}_{2}$ concentration of $20 \mathrm{ppm}$ may cause Bronchospasm and $50 \mathrm{ppm}$ causes extreme discomfort, but no injury in less than a 30 minute exposure. Finally, inhalation of $1000 \mathrm{ppm}$ more than 10 minutes causes death [15]. The Concentrations of $\mathrm{H}_{2} \mathrm{~S}$ and $\mathrm{SO}_{2}$ in two different conditions considered in this modeling scenario can be seen in Table 1. It is assumed that $\mathrm{H}_{2} \mathrm{~S}$ is completely oxidized during normal flaring.

\section{TABLE 1}

Concentrations of $\mathrm{H}_{2} \mathrm{~S}$ and $\mathrm{SO}_{2}$ in two different conditions considered in this modeling scenario [8]

\begin{tabular}{c|c|c}
\hline Conditions & Concerns & Release rate \\
\hline Flare flame out & $\mathrm{H}_{2} \mathrm{~S}$ & $100.63 \mathrm{kmole} / \mathrm{h}$ \\
\hline Normal flaring & $\mathrm{SO}_{2}$ & $100.63 \mathrm{kmole} / \mathrm{h}$ \\
\hline
\end{tabular}

\subsection{Exposure Assessment}

There has been a significant increase in awareness of environmental issues in recent years and there is a great concern among people over how their health is affected by environmental factors. Exposure assessment includes estimating the dose or concentration of the contaminant taken in by human or ecological receptors per unit of time. Characterization of the exposure setting, identification of exposure pathways and quantification of exposure are different steps in exposure assessment.

Gas dispersion modeling helps to predict the ground level concentration and deposition of air pollutants. One of the key elements of an effective dispersion modeling study is to choose an appropriate tool to match the scale of impact and complexity of a particular discharge [16].

In medium-complex atmospheric and topographical conditions as existed in the vicinity of Khangiran, Gaussianplume models can be used to produce reliable results. In more complex atmospheric and topographical conditions, advanced puff or particle models may be required to achieve a comparable degree of accuracy [16-17]. Furthermore, plume models are usually applicable to near field within $10 \mathrm{~km}$ from the source calculations. It is not wise to assume the meteorology will be the same greater than $10 \mathrm{~km}$ away as at the source [17-18]. Since the distance between the specified location (personnel dormitory), which should be considered as the critical point during flare flame out, from the flare stack is $1 \mathrm{~km}$, the plume model would be the proper model in comparison with puff model.

\subsubsection{Contaminants Transport Modeling using AERMOD}

There are some Gaussian plume dispersion models such as AERMOD, ISCST3, AUSPLUME and CTDMPLUS. AERMOD is the most common Gaussian plume dispersion model which is recommended to use [16-18]. AERMOD was developed in 1995, reviewed in 1998 and formally proposed by the USEPA as a replacement for ISCST3 in 2000 [18-19]. AERMOD is a near field, steady state guideline model. It uses boundary layer similarity theory to define turbulence and dispersion coefficients as a continuum, rather than as a discrete set of stability classes. Also, dispersion coefficients for unstable conditions are non-Gaussian, to represent the high concentrations that can be observed close to a stack under convective conditions [20]. The modeling system consists of AERMOD, as the main program, and AERMET and AERMAP as two pre-processors. AERMET is used to calculate boundary layer parameters. The meteorological interface uses these parameters to generate profiles of the needed meteorological variables. It passes all meteorological observations to AERMOD. In addition, AERMAP characterizes the terrain, and generates receptor grids for the dispersion model [16]. BREEZE® AERMOD [21] was used to model gas dispersion during flare flame out in the present study. This model is an air quality modeling system used to support both regulatory and non-regulatory modeling requirements worldwide.

\subsubsection{Contaminants Transport Modeling using UDM - PHAST}

DNV PHAST [22] as a comprehensive hazard analysis software tool is also used for gas dispersion modeling to corroborate AERMOD results. PHAST uses a proprietary dispersion model called the Unified Dispersion Model (UDM). It was formulated as a similarity model in which concentration and other variables are assumed to have a predefined profile. It also assumes generalized Gaussian profiles. Entrainment and spreading are calculated from a numerical (Runge-Kutta-Milne) solution to differential equations for mass, momentum and heat transfer between the cloud and its environment [23]. The UDM is formulated as an integral model. A set of differential equations is integrated to give the key variables as a function of distance or time. A number of algebraic equations are then solved to obtain other variables describing the dispersing cloud. The set of differential equations are basically the same for instantaneous and continuous releases, although they are integrated with respect to time at 
first and then with respect to distance. The same differential equations apply throughout all phases of dispersion [22]. Gas dispersion modeling was done for the flare flame out as well as normal flaring in this study with following considerations which can be seen in Table 2 and Table 3 (the stack diameter is $1.5 \mathrm{~m}$ and the stack length is $50 \mathrm{~m}$ ).

TABLE 2

Compositions of flare stream in flare header [8]

\begin{tabular}{c|c|c}
\hline Compositions & Mole flow $(\mathrm{kmol} / \mathrm{h})$ & Molar percent $(\%)$ \\
\hline Methane & 1059.40 & 87.42 \\
\hline Ethane & 5.66 & 0.46 \\
\hline Propane & 1.28 & 0.10 \\
\hline I-Butane & 0.37 & 0.03 \\
\hline N-Butane & 0.61 & 0.05 \\
\hline N-Pentane & 0.34 & 0.02 \\
\hline N-Hexane & 0.27 & 0.02 \\
\hline Carbon dioxide & 2.68 & 0.22 \\
\hline Hydrogen Sulfide & 100.63 & 8.34 \\
\hline Nitrogen & 40.50 & 3.34 \\
\hline
\end{tabular}

TABLE 3

Ambient air characteristics [10]

\begin{tabular}{c|c}
\hline Characteristics & Value \\
\hline Ambient temperature & $25^{\circ} \mathrm{C}$ \\
\hline Ambient pressure & $1 \mathrm{~atm}$ \\
\hline Day-time insolation & Moderate $\left(720143 \mathrm{cal} / \mathrm{m}^{2} \mathrm{~s}\right)$ \\
\hline
\end{tabular}

\subsubsection{Exposure Factors}

Following the chemical concentrations estimated based on two models (AERMOD and PHAST), which have similar results, the exposure factors for two different scenarios (average and worst case conditions) were considered as shown in Table 4.

\section{TABLE 4}

Exposure factors in two different scenarios [24]

\begin{tabular}{c|c|c}
\hline Factors & Average & Worst case \\
\hline Inhalation rate $\left(\mathrm{m}^{3} / \mathrm{h}\right)$ & 0.72 & 3.06 \\
\hline Exposure time (h/event) & 12 & 24 \\
\hline Exposure frequently (events/yr) & 269 & 365 \\
\hline Exposure duration (yr) carcinogenic & 70 & 70 \\
\hline Body (wt/kg) & 70 & 70 \\
\hline
\end{tabular}

The inhalation rates were received from USEPA [24] for two different conditions of slow and fast activity levels. For the average condition, the workers spend 12 hours inside the site, and in the worst case they may spend the entire day within the site. Some of the workers are not at the site during weekends, which is 96 days of the entire year. The average exposure duration was estimated for 70 years for a lifetime cancerous effect [24]. The dose received by a human due to inhalation of each metal (carcinogens intake) is calculated by the following equation:

Intake $=\frac{C_{\text {air }} * \text { Inhalation rate } * \text { Exposure time } * \text { Frequency }(1)}{\text { Body weight } * \text { Averaging time }}$

\subsection{Dose-Response Assessment}

Dose-response assessment is one of the steps of the risk assessment process that connects the likelihood and severity of damage on human health from exposures to different levels of risk agents. The reference concentration (RFC) is used to assess inhalation risks, where concentration refers to levels of contaminants in the air. For carcinogens, the slope of this straight line between dose and response, called the Slope Factor (SF) or cancer slope factor is used to estimate the risk at exposure levels. The RFCs and SFs used in this modeling scenario are presented in Table 5.

TABLE 5

Reference doses and carcinogenic slope factors for chemicals of concern [25-26]

\begin{tabular}{c|c|c}
\hline $\begin{array}{c}\text { Chemical } \\
\text { components }\end{array}$ & $\begin{array}{c}\text { Reference } \\
\text { concentration } \\
\left(\mathrm{mg} / \mathrm{m}^{3}\right)\end{array}$ & $\begin{array}{c}\text { Carcinogenic } \\
\text { Slope Factor } \\
(\mathrm{mg} / \mathrm{kg} / \mathrm{day})^{-1}\end{array}$ \\
\hline $\mathrm{H}_{2} \mathrm{~S}$ & 0.002 & 0.021 \\
\hline $\mathrm{SO}_{2}$ & 0.078 & --- \\
\hline
\end{tabular}

Previous investigations by NTP (National Toxicology Program), OSHA (Occupational Safety and Health Administration), or ACGIH (American Conference of Governmental Industrial Hygienists) did not classify $\mathrm{SO}_{2}$ as a carcinogenic substance. Therefore, the non-carcinogenic risk is only considered for $\mathrm{SO}_{2}$ in this scenario.

\subsection{Risk Characterization}

By integrating exposure assessment and toxicity assessment, which are discussed previously, the probability of negative effects is assumed. As sufficient information is available in the literatures to determine the toxicological benchmark (RFC and SF are available for the specific component), the quotient method for calculating the final risk value is used [27]. 
The data from Table 5 are used to calculate the Hazard Quotient (HQ) and the risk for carcinogens. The HQ is calculated from Equation (2), while the carcinogenic risk was calculated from Equation (3).

$$
\begin{gathered}
\mathrm{HQ}=\text { Non-carcinogenic intake }\left(\mathrm{mg} / \mathrm{m}^{3}\right) / \\
\text { Reference concentration }\left(\mathrm{mg} / \mathrm{m}^{3}\right) \\
\text { Risk }=\text { Carcinogenic intake }(\mathrm{mg} / \mathrm{kg} / \text { day }) \times \\
\text { Cancer slope factor }(\mathrm{mg} / \mathrm{kg} / \text { day })^{-1}
\end{gathered}
$$

If the HQ is less than 1, it shows that the risk is slight and little or no action is required. If the HQ is near 1, it shows uncertainty in the risk estimate and additional data is required. Finally, if the HQ is more than 1, it shows that the risk is greater and regulatory action may be indicated [28]. A single specified acceptable risk level, applicable for all carcinogens regulated by EPA is $10^{-6}$ (one death per million people). Whenever the risk of carcinogenic substance exceeds this value, it shows that the component has a carcinogenic effect [27].

\section{RESULTS AND DISCUSSION}

Implementing the four steps of EPA framework, with the contaminant concentrations released in two different conditions of normal flaring and flare flame out (see Tab.6) leads to the following results.
TABLE 6

Application of AERMOD and UDM

for gas dispersion modeling in Khangiran

\begin{tabular}{c|c|c}
\hline Condition & AERMOD & UDM \\
\hline Flare flame out & $\mathrm{H}_{2} \mathrm{~S}$ dispersion & $\begin{array}{c}\mathrm{H}_{2} \mathrm{~S} \text { dispersion } \\
\text { (impact area, restricted area) }\end{array}$ \\
\hline Normal flaring & - & $\mathrm{SO}_{2}$ dispersion \\
\hline
\end{tabular}

\subsection{Dispersion Modeling Results using AERMOD}

Figure 3 illustrates gas dispersion due to flare flame out condition in the study region. This figure shows that the personnel dormitory is covered by a plume with a concentration of more than $500 \mathrm{ppm}$.

\subsection{Dispersion Modeling Results using PHAST}

To study the gas dispersion conditions, two areas have been considered: the restricted and the impact area. The restricted area is the area within the boundaries of the installation and hence is under control of the company, either automatically through appropriate systems or manually. The impact area is the area that extended beyond the boundaries of the installation but is nevertheless affected permanently by normal

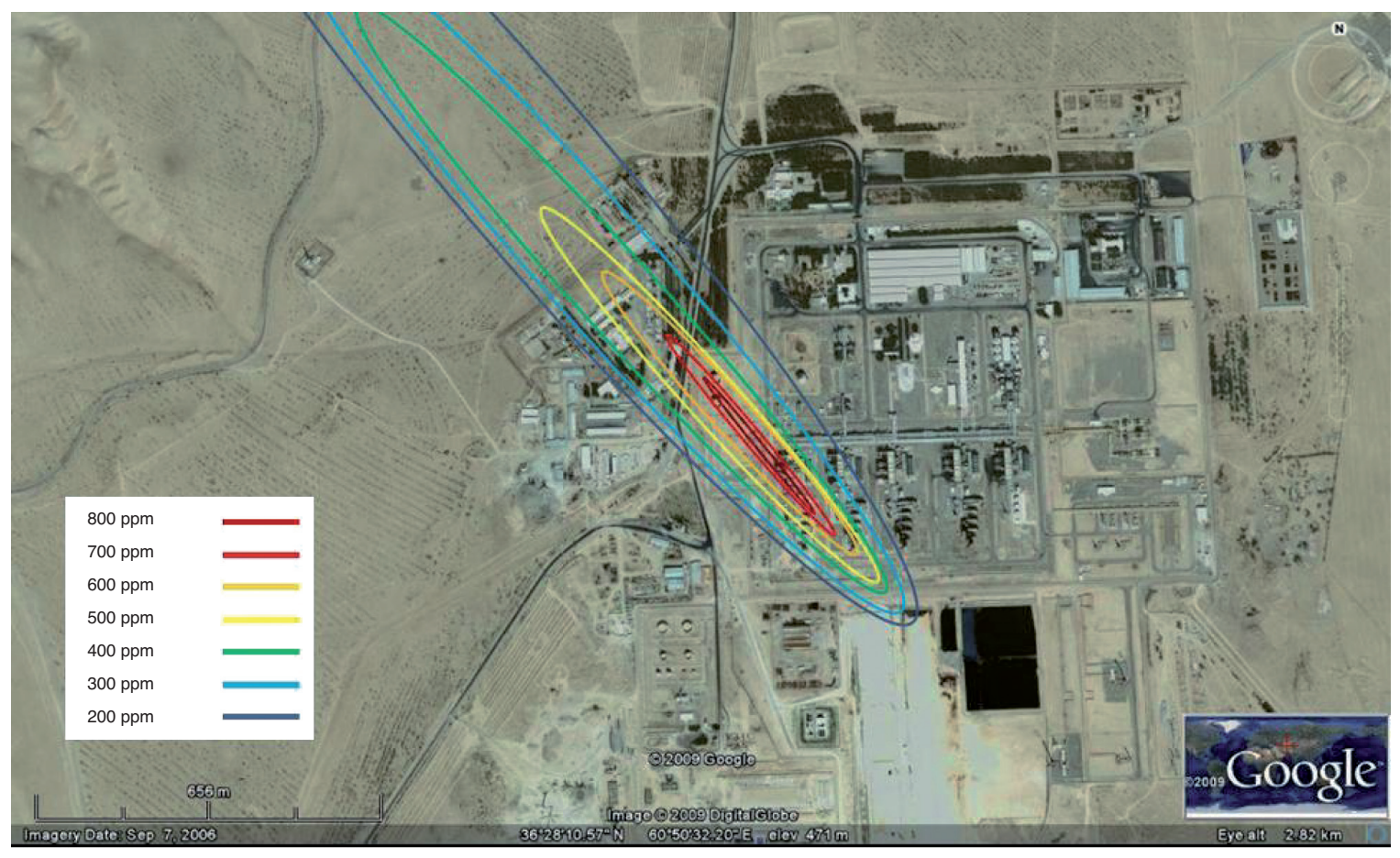

Figure 3

Gas dispersion due to flare flame out. 


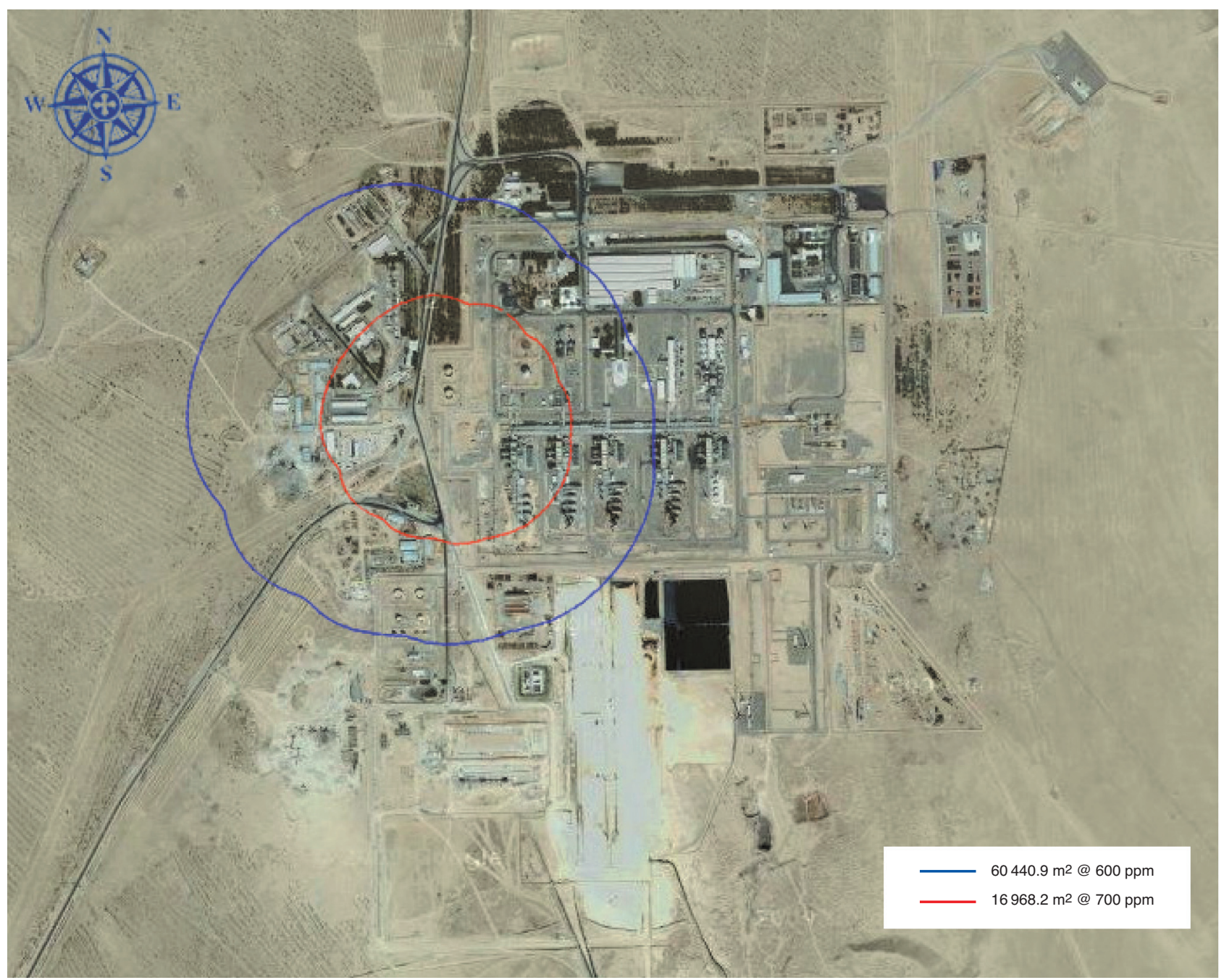

Figure 4

The maximum concentration of $\mathrm{H}_{2} \mathrm{~S}$ within the restricted area.

operation of the facility or exceptionally by the consequences of an emergency situation. The restricted area shall be always contained inside the impacted area. The calculations have been done for the worst flare gas stream containing 8 molar percent $\mathrm{H}_{2} \mathrm{~S}$ and hydrocarbon content of mostly methane. The flare burning assumed to be complete, so the combustion calculations have been done for the complete combustion situations. The simulations have been done by PHAST software. Results are shown in Figure 4-6.

The maximum concentration of $\mathrm{H}_{2} \mathrm{~S}$ in the restricted area has been illustrated in Figure 4. As shown in this figure, the hazard distance for refinery employee inhalation is a circle with a $1470 \mathrm{~m}$ radius. Therefore, in the particular climate conditions in which the wind direction might be changed toward the working area and dormitory, the flare flame out would have the irremediable consequence and shall be con- sidered. Also, the flare flame out in this condition would be important for the public, as it is drawn in Figure 5. In Figure 6 , the maximum concentration of $\mathrm{SO}_{2}$ dispersion for the impact and the restricted area has been shown. As demonstrated in this figure, the hazard distance for $\mathrm{SO}_{2}$ inhalation is more than $12000 \mathrm{~m}$, which includes the entirety of the working area as well as the personnel dormitory. Therefore, the continuous flaring in an emergency situation would endanger the employee and it shall be considered during the emergency response plan.

\subsection{Risk Estimation}

The concentrations of $\mathrm{SO}_{2}$ and $\mathrm{H}_{2} \mathrm{~S}$ in two different conditions of normal flaring and flare flame out are calculated, as can be seen in Table 7 . 


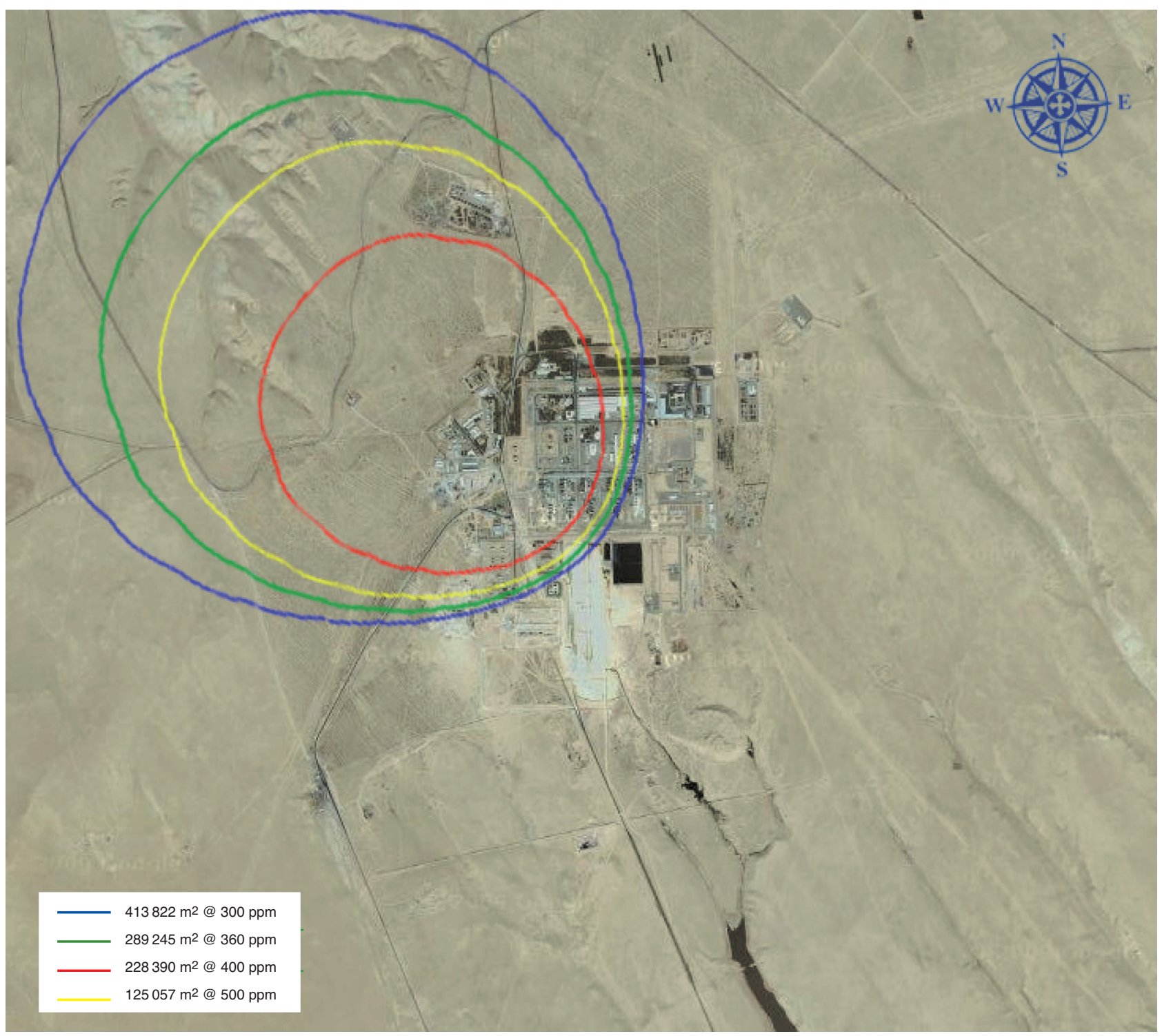

Figure 5

The maximum concentration of $\mathrm{H}_{2} \mathrm{~S}$ within the impact area.

After finding the concentrations of these chemicals based on two different conditions considered in this modeling scenario, HQs are calculated to evaluate the hazardous effect of $\mathrm{SO}_{2}$ in the normal flaring condition. As illustrated in Table 8, the HQs in both areas (NF1 \& NF2) are grater than the criteria, which is 1 . It shows the high non-carcinogenic risk of inhaling $\mathrm{SO}_{2}$ in these areas.

Also, the values of HQs calculated based on the inhalation of $\mathrm{H}_{2} \mathrm{~S}$ in different areas (FFO1 to FFO4) in the flare flame out condition are far above the criteria. This shows a great risk of inhalation of $\mathrm{H}_{2} \mathrm{~S}$ in the flare flame out condition.
Comparing the results of carcinogenic health risk with the criteria $\left(10^{-6}\right)$ shows that, there is a great carcinogenic health risk by inhaling $\mathrm{H}_{2} \mathrm{~S}$ during flare flame out condition in both scenarios (normal and worst case) considered in this study. $\mathrm{H}_{2} \mathrm{~S}$ release in the flare flame out condition can be so dangerous, that it could result in having the harmful effects on human health. Therefore, the following recommendations selected from previous investigations [29-31, 8] are necessary to be considered for precluding the flare flame out and limiting these hazardous conditions:

- Use of an automatic flame monitoring device to warn of flameout conditions; 
TABLE 7

Concentrations of CPC in two different conditions considered in this modeling scenario

\begin{tabular}{c|c|c}
\hline \multicolumn{3}{c}{ Normal flaring } \\
\hline Area & $\mathrm{SO}_{2}$ concentration $(\mathrm{ppm})$ & No. of employees in the area \\
\hline $\mathrm{NF}^{*}$ & 2 & 200 \\
\hline $\mathrm{NF} 2$ & 5 & 220 \\
\hline \multicolumn{2}{|c}{ Flare flame out } \\
\hline Area & $\mathrm{H}_{2}$ S concentration (ppm) & No. of employees in the area \\
\hline FFO1** & 300 & 170 \\
\hline FFO2 & 360 & 200 \\
\hline FFO3 & 400 & 200 \\
\hline FFO4 & 500 &
\end{tabular}

* NF1: Normal Flaring area 1. ** FFO: Flare Flame Out area 1

TABLE 8

Calculating hazard quotients and cancer health risk for different scenario

\begin{tabular}{c|c|c|c}
\hline \multicolumn{3}{c}{ Inhalation of $\mathrm{SO}_{2}$ in normal flaring } \\
\hline \multicolumn{2}{c}{ Area } & \multicolumn{2}{c}{ Hazard quotient } \\
\hline \multicolumn{2}{c}{$\mathrm{NF1}$} & \multicolumn{2}{c}{$0.68 \mathrm{e}+2$} \\
\hline \multicolumn{3}{c}{ IF2 } & \multicolumn{2}{c}{$1.71 \mathrm{e}+2$} \\
\hline & Hazard quotient & Cancer health risk \\
\hline Area & & Average & Worst case \\
\hline FFO1 & $2.12 \mathrm{e}+3$ & 0.58 & 6.72 \\
\hline FFO2 & $2.55 \mathrm{e}+5$ & 0.69 & 8.07 \\
\hline FFO3 & $2.83 \mathrm{e}+5$ & 0.77 & 8.95 \\
\hline FFO4 & $3.54 \mathrm{e}+5$ & 0.97 & 11.21 \\
\hline
\end{tabular}

- Provision of a liquid Knock Out (KO) drum, which is equipped with high level alarms to warn of an excessive accumulation of liquid;

- Prevention of the introduction vapors into the system when it is not operational;

- Automate the ignition sequence using continuous pilot flame monitoring;

- Use direct electrical ignition of pilots with flame front only as a back-up system to cover for electrical problems with inaccessible equipment;

- Use pilot burners specially adapted for high inert atmospheres wherever high inert purge flows are likely;

- Use Flare Gas Recovery System (FGRS). Typically, the gas is recovered from a vent header feeding a flare. Depending on flare gas composition, the recovered gas may be recycled back into the process for its material value or used as fuel gas. FGRS is commonly used in

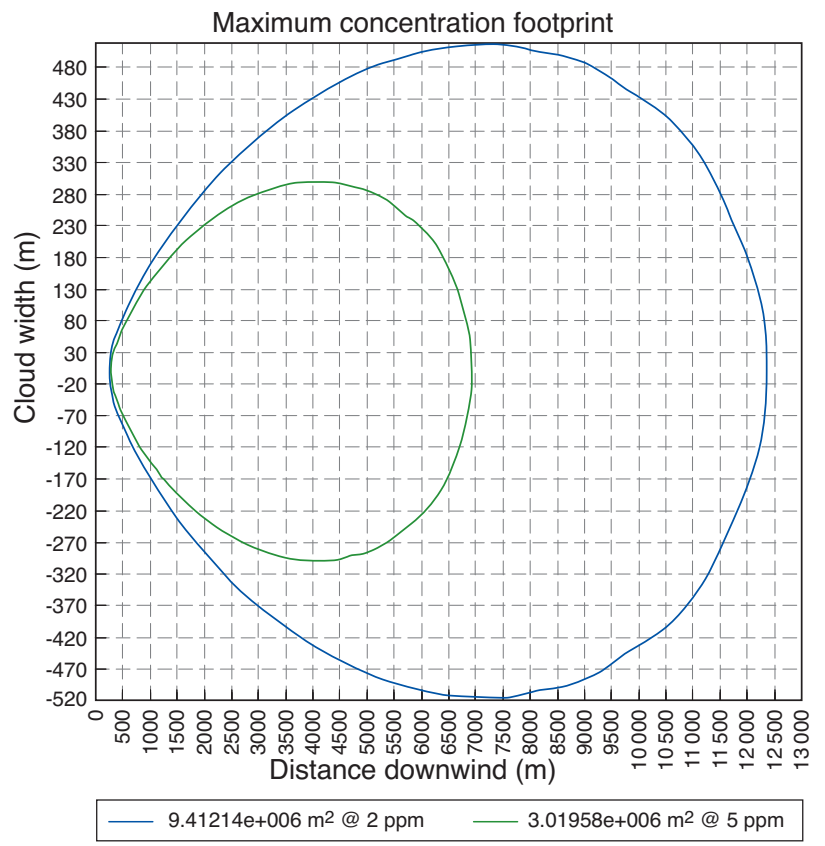

Figure 6

The maximum concentration of $\mathrm{SO}_{2}$ for impact and restricted areas.

refineries to recover flammable gases for reuse as fuel for process heaters.

Zadakbar et al. proposed an FGRS for the Khangiran gas facilities. It has a modular design and comprises three separate and parallel trains capable of handling various gas loads and compositions. Gas emissions will be decreased up to $70 \%$ by using such recovery system [1]. Thus it could be a unique suggestion to reduce the hazardous consequences of flare flame out condition.

\section{CONCLUSIONS}

Flaring is the process of burning waste gases which creates emissions such as sulfur oxides $\left(\mathrm{SO}_{x}\right)$ and greenhouse gases $\left(\mathrm{CO}_{2}\right.$ and $\left.\mathrm{CO}\right)$. In certain conditions i.e. storm, heavy rain, strong wind, long serviced pilot, etc., flare may lose the flame. Analysis of toxic effects of $\mathrm{H}_{2} \mathrm{~S}$ during flare flame out as well as analysis of toxic effects of $\mathrm{SO}_{2}$ which is released during normal flaring in Khangiran natural gas process facility has been evaluated. Since there is a large amount of sour gas which is burnt off in the Khangiran, flare flame out, during particular climate condition when wind blows from southeast to northwest, could have fatal effects on employees inside the site and dormitory. Environmental Risk Assessment is used as a tool to evaluate the hazardous effect of toxic 
gases on human health. The fate and transport of the contaminants $\left(\mathrm{H}_{2} \mathrm{~S}\right.$ and $\left.\mathrm{SO}_{2}\right)$ are modeled using AERMOD and UDM. In medium-complex atmospheric and topographical conditions, with relatively simple effects, as may be seen in vicinity of Khangiran, Gaussian-plume models can produce reliable results. Comparing the results of cancer and non-cancer risk values with the existing guidelines shows that the employees are at risk of inhaling carcinogenic and non-carcinogenic contaminants. Both values of carcinogenic and non-carcinogenic risk are much greater whenever the flare flame out condition happens. Moreover, living with such a condition for a long time leads to death. Therefore, evaluating the flare conditions regularly and assessing alternatives to preclude the flare flame out is required.

\section{ACKNOWLEDGMENT}

The authors gratefully acknowledge the financial support of Qatar National Research Foundation (QNRF) under NPRP grant, and the material support of Nargan Consulting Engineers.

\section{REFERENCES}

1 Zadakbar O., Vatani A., Karimpour K. (2008) Flare Gas Recovery in Oil and Gas Refineries, Oil Gas Sci. Technol. - Rev. IFP 63, 6, 705-711. DOI: 10.2516/ogst:2008023.

2 Hemminki K., Neimi M.L. (1982) Community study of spontaneous abortion: relation to occupation and air pollution by sulfur dioxide, hydrogen sulfide and carbon disulfide, Int. Arch. Occ. Env. Hea. 51, 55.

3 Jones T.D., Walsh P.J., Watson A.P., Owen B.A., Barnthouse L.W., Sanders D.A. (1988) Chemical scoring by a Rapid Screening of Hazard (RASH) method, Risk Analysis 8, 99-118.

4 Strosher M. (1996) Investigations of Flare gas Emissions in Alberta, Final report to Environment Canada, Alberta Energy Utilities Board and the Canadian Association of Petroleum Producers.

5 Kindzierski W.B. (2000) Importance of human environmental exposure to hazardous air pollutions from gas flares, Environ. Rev. 8, 1, 41-62.

6 Nazir M., Khan F., Amyotte P., Sadiq R. (2008) Subsea release of oil from a riser: An ecological risk assessment, Risk Analysis 28, 5, 1173-1196.

7 US EPA (1991) Risk assessment for toxic air pollutions: A citizen's guide-EPA 450/3-90-024.

8 Zadakbar O. (2008) Flare Gas Recovery in Oil and Gas Refineries, Master Thesis, Department of Chemical Engineering, University of Tehran, Iran.

9 Google Map (2009) (www.google.com).
10 IMO, Iran Meteorological Organization (2009) http://www.razavimet.gov.ir.

11 Lewis R.J. (1996) Sax's Dangerous Properties of Industrial Materials, 9th ed., Vol. 1, Van Nostrand Reinhold, New York, NY.

12 Zenz C., Dickerson O.B., Horvath E.P. (1994) Occupational Medicine, 3rd ed., St. Louis, MO.

13 US EPA (1980) Health and Environmental Effects Profile for Hydrogen Sulfide.

14 Matheson (1983) Guide to Safe Handling of Compressed Gases, 2nd ed., p. 15.

15 Thienes C., Haley T.J. (1972) Clinical Toxicology, 5th ed., Lea and Febige, Philadelphia, p. 198.

16 Alberta Environment (2009) (http://environment.alberta.ca).

17 NZME, New Zeeland Ministry for Environment (2009) (http://www.mfe.govt.nz).

18 USEPA (2009) AERMOD implementation guide.

19 Keith C.S., Joan G. (2007) Comparison of the Industrial Source Complex and AERMOD Dispersion Models: Case Study for Human Health Risk Assessment, Air Waste Manage. Assoc. 57, 1439-1446.

20 American Meteorological Society AMS (2009) Glossary of Meteorology.

21 Trinity Consultants, Inc. (2009) BREEZE Software \& Data, http://www.breeze-software.com/AERMOD.

22 DNV (2009) Det Norske Veritas, DNV PHAST (www.dnc.com).

23 Jamin K., Kima H., Soa W., Kimb K., Yoona E. (2009) Safety Assessment of LNG Terminal Focused on the Consequence Analysis of LNG Spills, Proceedings of the 1st Annual Gas Processing Symposium, 10-12 January, Doha, Qatar.

24 USEPA (1989) Exposure factors handbook, EPA/600/8-89/043.

25 USEPA (2005) Chronic and acute toxicity creceria compiled for compounds not included in USEPA's HHRAP, Appendix B.

26 Benner T.C. (2004) Brief Survey of EPA Standard-Setting and Health.

27 Abbassi R. (2010) Mining treatment effluent pond modeling: a risk based approach, PhD thesis, Memorial University of Newfoundland, St.John's, NL, Canada.

28 Canadian Council of Ministers of the Environment (CCME) (1996) A framework of ecological risk assessment: General guidance, The national contaminated sites remediation program, Winnipeg, Manitoba, Canada.

29 Nolan D.P. (1996) Handbook of fire and explosion protection engineering principles for oil, gas, chemical, and related facilities.

30 Kent B. (2002) Environmental Quality Management, Air Quality Permitting Technical Memorandum Permit to Construct No. 083-00085 Twin Falls, Idaho, Inc. Project No. P-000417, March 25.

31 Shore D. (1996) Making the flare safe, J. Loss Prevent. Proc. Ind. 9, Issue 6, November.

Final manuscript received in September 2010 Published online in January 2011

\section{Copyright (C) 2011 IFP Energies nouvelles}

Permission to make digital or hard copies of part or all of this work for personal or classroom use is granted without fee provided that copies are not made or distributed for profit or commercial advantage and that copies bear this notice and the full citation on the first page. Copyrights for components of this work owned by others than IFP Energies nouvelles must be honored. Abstracting with credit is permitted. To copy otherwise, to republish, to post on servers, or to redistribute to lists, requires prior specific permission and/or a fee: Request permission from Information Mission, IFP Energies nouvelles, fax. +33147527096, or revueogst@ifpen.fr. 